\title{
Electrical storm: An unusual manifestation of coronary ectasia
}

\author{
Tormenta eléctrica: una manifestación inusual de ectasia coronaria \\ Luis M. González-Galván ${ }^{*}$, Diego Araiza-Garaygordobil'1 Jorge L. Vargas-Estrada1 ${ }^{1}$, and \\ Edgar Illescas-González² \\ ${ }^{1}$ Coronary Unit; ${ }^{2}$ Department of Hemodynamics, Instituto Nacional de Cardiología Ignacio Chávez, Mexico City, Mexico
}

\section{Introduction}

Coronary ectasia (CE) is a diffuse disease of the vessel that causes a dilation larger than 1.5 times in comparison with an adjacent segment of a healthy artery. CE incidence ranges from 0.3 to $4.9 \%$ in the general population ${ }^{1}$. Despite its relative frequency, CE clinical presentation, origin, management, and prevention continue to be a subject of debate and continuous medical research ${ }^{2}$. We report the case of a CE uncommon presentation: electric storm.

\section{Clinical case}

A 42-year-old man with a history of long-standing type 2 diabetes mellitus with intense tobacco consumption for 20 years. He attended the emergency department of our hospital with a 24-h history of oppressive chest pain radiating to the left shoulder and associated with dyspnea. On physical examination, vital signs stood out: HR 84 bpm, BP 106/70 mmHg, RR 22 brpm, and $86 \% \mathrm{SpO}_{2}$, as well as the presence of subcrackling rales in both lung bases. Precordium with rhythmic heart sounds, no murmurs or other anomalies. Admission electrocardiogram on sinus rhythm, with a lower inactivable zone (QS). During emergency department examination, profuse diaphoresis occurred suddenly, and ventricular tachycardia (VT) was documented (Fig. 1); the patient was hemodynamically stable. The treatment was started with amiodarone, without the condition being resolved; due to the persistence of symptoms, electrical cardioversion was carried out on three occasions, unsuccessfully. Intravenous (i.v.) lidocaine was administered, whereby sinus rhythm was obtained for $30 \mathrm{~s}$, to again return to VT. Orotracheal intubation was decided, and the patient was brought to diagnostic coronagraphy, which reported CE in all three main arteries, with significant thrombotic load (TIMI IV thrombus in the right coronary artery and TIMI IV thrombus in the circumflex branch), as well as TIMI II slow flow (Fig. 2). A tirofiban intracoronary dose was administered, as well as in situ thrombolysis with intracoronary tenecteplase in the right coronary artery (responsible for the infarction). Intra-aortic counterpulsation balloon was placed due to VT persistence and, still in the operation room, electrical cardioversion was performed for the $4^{\text {th }}$ time, with sinus rhythm and hemodynamic state improvement being obtained. The patient was transferred to the coronary unit, where he showed improvement during the next few hours.

\section{Discussion}

In 1761, Morgagni ${ }^{3}$ first described CE anatomical characteristics in a patient with syphilis, but the term ectasia (from Latin ectasis, dilation) was coined by Bjork in 1966. In more than half the cases, CE is associated with atherosclerotic coronary artery disease, but on less frequent occasions, it has been related to

\section{Correspondence:}

*Luis M. González Galván

E-mail: dr.galvan1206@gmail.com
Date of reception: 11-12-2018

Date of acceptance: 13-08-2019 DOI: 10.24875/ACME.M20000116
Available online: 04-09-2020 Arch Cardiol Mex (Eng). 2020;90(2):207-209 www.archivoscardiologia.com 2604-7063 / @ 2019 Instituto Nacional de Cardiología Ignacio Chávez. Published by Permanyer. This is an open access article under the CC BY-NC-ND license (http://creativecommons.org/licenses/by-nc-nd/4.0/). 


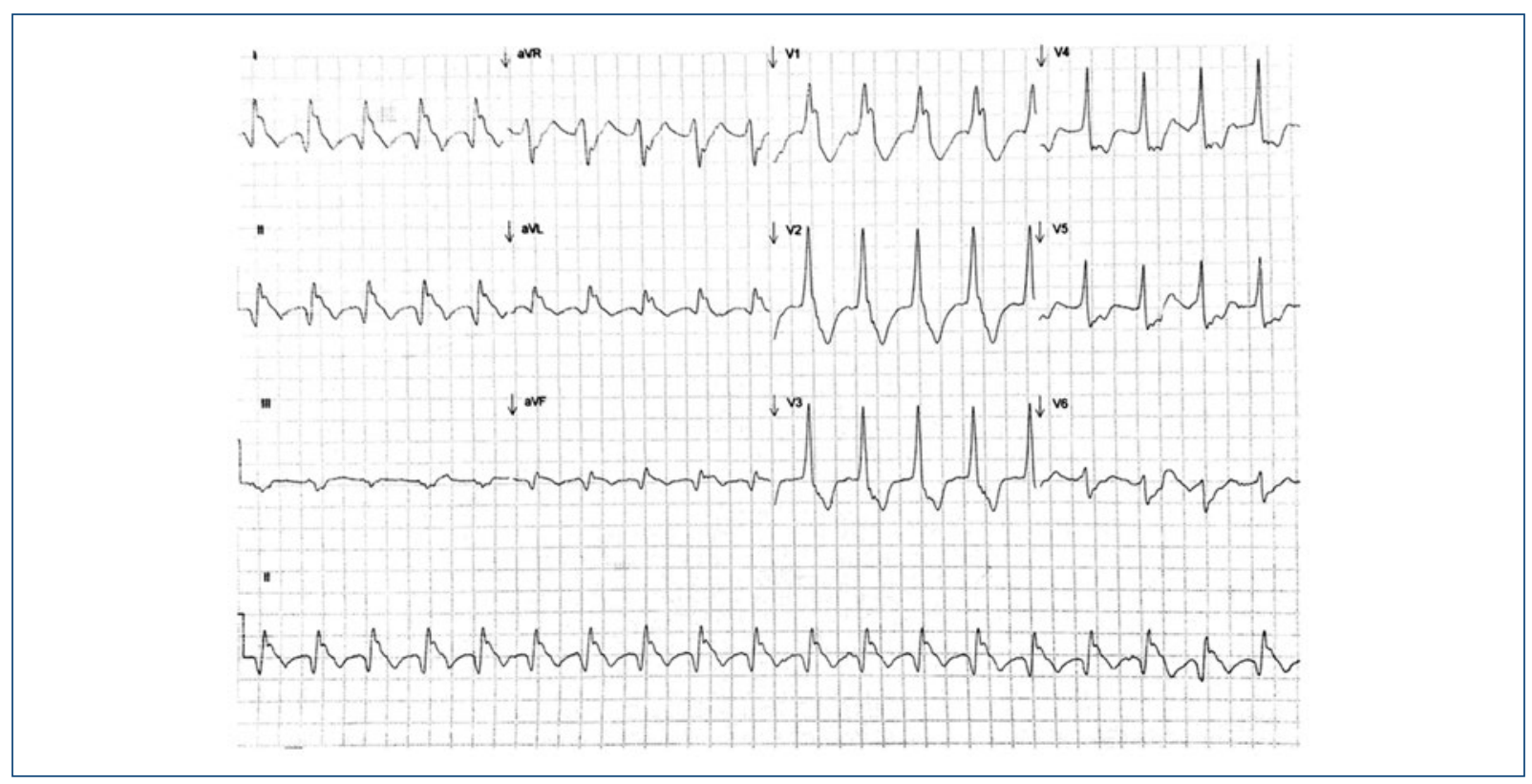

Figure 1. ECG shows wide-complex, monomorphic tachycardia with the left horizontal axis and RBBB morphology, suggesting that ventricular tachycardia site of origin may have been be the interventricular septum left side basal segments.

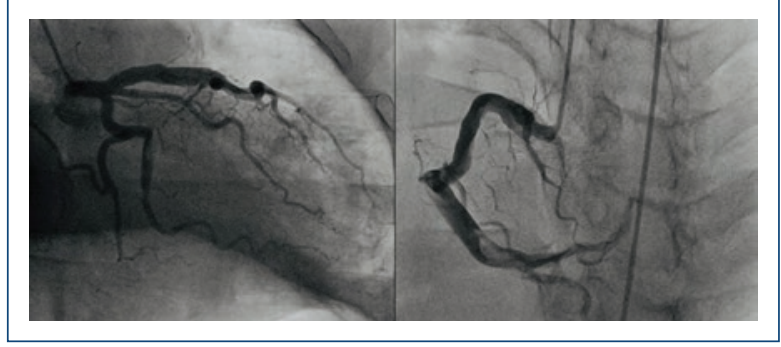

Figure 2. Coronarography with the presence of ectatic arteries.

other pathological conditions such as exposure to herbicides, Takayasu disease, polyarteritis nodosa, trauma, or direct vascular injury. ${ }^{5}$ All three coronary arteries can be affected by $\mathrm{CE}$, but in $75 \%$ of patients, it is an isolated artery that is ectatic ${ }^{5}$. Markis et al. proposed a form to classify CE according to the degree of severity of the condition. In decreasing order of severity: diffuse ectasia of two or three vessels (type I), a diffuse disease in one vessel and localized disease in another vessel (type II), and diffuse ectasia in one vessel (type III) and localized segmental ectasia (type IV) ${ }^{4}$. As for the clinical presentation of these patients, stable chronic angina tends to be the most common ${ }^{7}$. Acute coronary syndromes, both with and without ST-segment elevation, can occur due to blood flow alteration secondary to distal embolization or thrombotic occlusion of an ectatic segment 8.9 .

In this case, given that presentation was as wide-complex tachycardia, the correct diagnosis of the tachycardia origin is essential for decision making, and there are algorithms that suggest how to enable making a differentiation between supraventricular tachycardia and VT, using both Brugada and Verckei diagnostic criteria $^{10,11}$. The patient electrocardiogram showed an initial R-wave in the aVR lead, as well as that its width was longer than $40 \mathrm{~ms}$, thus meeting two Verckei criteria to be classified as VT. On the other hand, although according to Brugada criteria, there was no absence of $\mathrm{RS}$ in all precordial leads, R-to-S time was shorter than $100 \mathrm{~ms}$, there is no V-A dissociation, it met other morphological criteria for VT in V1 and V6 in the presence right bundle branch block.

The term "electrical storm" describes a state of heart electrical instability characterized by a grouping of VT or ventricular fibrillation (VF) recurrent episodes in a short period of time. In recent years, implantation of an automated implantable cardioverter-defibrillator (AICD) has significantly improved the survival of patients with VT/VF. However, electrical storms are associated with high mortality and morbidity and have a negative impact on long-term clinical outcomes ${ }^{15}$. Although there 
is no consensus on the definition of an electrical storm, it is generally accepted that the appearance of $>2$ VT separate episodes/or $>2$ VF episodes or $>3$ appropriate AICD therapies for VT/VF in a $24-h$ period constitute an electrical storm episode.

CE has been associated with a secondary slow coronary flow phenomenon, characterized by a distal delay in coronary vessel opacification in the absence of significant epicardial coronary artery stenosis ${ }^{6}$. The pathogenic mechanism is not fully understood. Clinically, this phenomenon occurs in young men and smokers who are admitted as having acute coronary syndrome ${ }^{7}$, and it has been associated with malignant arrhythmias and sudden cardiac death ${ }^{12-14}$.

We consider that the coronary slow flow phenomenon played a pivotal role in the pathophysiology of the electrical storm in the described case. There is much that remains to be elucidated about the interrelation existing between $\mathrm{CE}$, coronary flow dynamics, and arrhythmic load in the context of the ischemic coronary syndrome. To the best of our knowledge, this is the first case that reports a direct association of CE and electrical storm.

\section{Funding}

None.

\section{Conflicts of interest}

None.

\section{Ethical responsibilities}

Protection of people and animals. The authors declare that no experiments were performed on humans or animals for this investigation.
Confidentiality of data. The authors declare that they have followed the protocols of their work center on the publication of the patient data.

Right to privacy and informed consent. The authors have obtained informed consent from the patients and/or subjects referred to in the article. This document is in possession of the corresponding author.

\section{References}

1. Hartnell GG, Parnell BM, Pridie RB. Coronary artery ectasia. Its exercise induced myocardial ischemia in isolated coronary artery prevalence and clinical significance in 4,993 patients. Br Heart J. 1985;54:392-95.

2. Mangina $A$, Cokkinos D. Coronary artery ectasia: imaging, functional assessment and clinical implications. Eu Heart J. 2006;27:1026-31.

3. Morgagni JB. De sedlbus, et causis morborum per anatomen indagatis. 1761. Tomus primus, Liber II, Epist 27, Article 28, Venetiis.

4. Markis JE, Joffe CD, Cohn PF, Feen DJ, Herman MV, Gorlin R. Clinical significance of coronary arterial ectasia. Am J Cardiol. 1976;37:217-22.

5. Pinar-Bermúdez E, López-Palop R, Martínez-Luengas IL, Cortés-Sánchez R, Carrillo-Sáez P, Rodríguez-Carreras R, et al. Ectasia coronaria: prevalencia, características clínicas y angiográficas. Rev Esp Cardiol. 2003;56:473-9.

6. Beltrame JF, Limaye SB, Horowitz JD. The coronary slow flow phenomenon-a new coronary microvascular disorder. Cardiology. 2002; 97:197-202.

7. Aboeata AS, Sontineni SP, Alla VM, Esterbrooks DJ. Coronary artery ectasia: current concepts and interventions. Front Biosci Elite Ed. 2012;4:300-10.

8. Rath S, Har-Zahav Y, Battler A, Agranat O, Rotstein Z, Rabinowitz B, et al. Fate of nonobstructive aneurysmatic coronary artery disease: angiographic and clinical followup report. Am Heart J. 1985;109(4):785-91.

9. Akyürek O, Berkalp B, Sayin T, Kumbasar D, Kervancioğlu C, Oral D. Altered coronary flow properties in diffuse coronary artery ectasia. Am Heart J. 2003;145(1):66-72.

10. Vereckei A, Duray G, Szénási G, Altemose GT, Miller JM. New algorithm using only lead aVR for differential diagnosis of wide QRS complex tachycardia. Heart Rhythm. 2008;5(1):89-98.

11. Brugada P, Brugada J, Mont L, Smeets J, Andries EW. A new approach to the differential diagnosis of a regular tachycardia with a wide QRS complex. Circulation. 1991;83(5):1649-59.

12. Wozakowska-Kapłon B, Niedziela J, Krzyzak P, Stec S. Clinical manifestations of slow coronary flow from acute coronary syndrome to serious arrhythmias. Cardiol J. 2009;16:462-8.

13. Saya S, Hennebry TA, Lozano P, Lazzara R, Schechter E. Coronary slow flow phenomenon and risk for sudden cardiac death due to ventricular arrhythmias: a case report and review of literature. Clin Cardiol. 2008;31:352-5.

14. Maruyama M, Yamamoto T. Electrical storms: Recent advances. En: Kibos AS, Knight BP, editores. Cardiac arrhythmias: From basic mechanism to state-ofthe-art management. Londres: Springer-Verlag; 2014. pp. 285-92.

15. Gao D, Sapp JL. Electrical storm: definitions, clinical importance, and treatment. Curr Opin Cardiol. 2013;28:72-9. 